\title{
Ultra Performance Liquid Chromatography Tandem Mass Spectrometry Method for the Measurement of Anandamide in Human Plasma
}

Patricia M. W. Lam, Timothy H. Marczylo, Mona El-Talatini, Mark Finney, Vijaianitha Nallendran, Anthony H. Taylor, Justin C. Konje

Endocannabinoid Research Group, Reproductive Sciences Section, Department of Cancer Studies and Molecular Medicine, University of Leicester, Robert Kilpatrick Clinical Sciences Building, Leicester Royal Infirmary, Infirmary Road, Leicester, LE2 7LX. United Kingdom.

Correspondence and reprint requests to:

Justin C. Konje Tel: +44 116252 5826, Fax: +44 116252 5846, E-mail: jck4@le.ac.uk

Running Title: Measurement of anandamide in human plasma

Abbreviations: AEA, $\mathrm{N}$-arachidonoylethanolamine (anandamide); AEA-d8, octo-deuterated anandamide; LOD, limit of detection; LOQ, limit of quantification; RSD, relative standard deviation; UPLC, ultra performance liquid chromatography, HPLC, high performance liquid chromatography; MS/MS, tandem mass spectrometry

Keywords: anandamide, endocannabinoid, liquid chromatography, mass spectrometry, plasma

The authors affirm that they have no conflicts of interest.

Formatted: Right: $0.63 \mathrm{~cm}$ 


\section{Abstract}

Anandamide ( $\mathrm{N}$-arachidonoylethanolamine, AEA) is an endocannabinoid present in human plasma that is associated with several physiological functions and disease states. Significant variability in AEA plasma concentrations have been reported between studies, because quantification of AEA is fraught with methodological difficulties. A rapid, highly sensitive, robust, specific and highly reproducible ultra high pressure liquid chromatography-tandem mass spectrometry (UPLC-MS/MS) method is described here for the analysis of AEA in human plasma. This fully validated method using octa-deuterated AEA (AEA-d8) as an internal standard, represents an improvement over previous analyses in terms of run time (4 $\mathrm{min}$ ), limit of detection (0.055 fmol on column, $18.75 \mathrm{fmol} / \mathrm{mL}$ plasma), precision (relative standard deviations of $3.7,3.9$ and $4.8 \%$ for $1.66,6.65$ and $133 \mathrm{fmol}$ on column) and accuracy (97.5-104.5\%). AEA analysis was linear over the range 0.23 to $19 \mathrm{nM}$ (1.66 to $133 \mathrm{fmol}$ on column). To demonstrate the usefulness of this method for the measurement of AEA levels in clinical samples, plasma obtained from female volunteers at different stages of the menstrual cycle and pregnant women were assayed. Plasma AEA concentrations were significantly $(P=0.0078)$ lower in the luteal phase of the menstrual cycle compared to the follicular phase. In pregnancy, the concentrations were lowest in the first and second trimesters with levels comparable to those observed in the luteal phase of the menstrual cycle and modestly increased in the third trimester. The highest plasma AEA levels were observed in women in active labour, and these were significantly $(P=0.0147)$ higher than those observed in women at term but not in active labour. Post-menopausal women had AEA concentrations comparable to 
levels observed during the luteal phase of pre-menopausal women and were significantly $(P=0.0389)$ lower than $A E A$ plasma concentrations obtained during the follicular phase. The sensitivity and precision of the validated method described here suggests that this method is suitable for the analysis of AEA in clinical samples and may be utilised for the investigation of biomatrices containing limited amounts of AEA.

Formatted: Right: $0.63 \mathrm{~cm}$ 


\section{Introduction}

Anandamide ( $N$-arachidonoylethanolamine; AEA), is an unsaturated fatty acid derivative that was first identified in porcine brain [2] and has since been characterised as an endogenous ligand for the cannabinoid receptors, CB1 and CB2 [3]. Other endocannabinoids have since been identified including 2arachidonoylglycerol, noladin ether and $\mathrm{N}$-arachidonoyl dopamine [3-5].

AEA is released from cell membrane phospholipid precursors in response to depolarizing agents, hormones, and neurotransmitters on demand rather than being released from intracellular stores [6] and is eliminated by carriermediated cellular uptake through an uncharacterised specific membrane transporter [7], and subsequent hydrolysis by the enzyme, fatty acid amide hydrolase [6].

AEA stimulates various physiological effects including hypothermia, antinociception, vasodilation and anti-inflammatory effects $[3,8]$ and has been implicated in several physiological functions and conditions ranging from analgesia, reproduction, modulation of vascular tone, obesity, cancer, schizophrenia and multiple sclerosis [9].

In the reproductive system, exocannabinoids adversely affect foetal growth and uterine implantation, and are associated with foetal growth restriction and premature birth in humans [10-12]. Data from our group and others have demonstrated that plasma AEA levels vary throughout the menstrual cycle; levels in the luteal phase are lower than those in the follicular phase but similar to those in early pregnancy $[1,13]$. In mice, AEA has been implicated

Formatted: Right: $0.63 \mathrm{~cm}$ 
in the synchronous development of the blastocyst and the endometrium to the stage where the former is ready for implantation and the latter is ready to receive the blastocyst [14]. In CB1 receptor knock-out animal models, the development of the endometrium has been demonstrated to be inadequate and in addition, transport along the oviducts is inhibited [14]. Despite the apparent importance of endocannabinoids in the regulation of reproduction, a major constraint to improving our understanding of this relationship has been the inability to process more than a few samples at a time, due to lengthy AEA retention times with total run times from $35 \mathrm{~min}$ to in excess of $60 \mathrm{~min} / \mathrm{sample}$ $[1,15-17]$.

AEA measurements using single quadrapole HPLC-MS have detected AEA in several biomatrices including plasma, seminal fluid, breast milk and oviductal fluid $[1,15-17]$. These studies are limited however by the lack of rigorous validation data and analyses times of $30 \mathrm{~min}$ or greater. Measurements of endocannabinoids by high performance liquid chromatography tandem mass spectrometry (HPLC-MS/MS) in three recent studies in rat brain and human plasma have reduced analysis times to between 7-15 min. However, these studies have either a: not been validated [18], b: are used for brain tissues not plasma [19] or c: had comparatively poor limits of detection [20].

Although plasma AEA concentrations have been determined in a number of human cohorts, the mean AEA concentrations reported have varied considerably between studies, from $0.37 \mathrm{nM}$ [18] and $2.58 \mathrm{nM}$ [21] to $3.73 \mathrm{nM}$ [20]. This 10-fold variability between studies suggests that plasma AEA 
concentrations can be difficult to determine routinely and thus a robust, validated analysis method is needed.

We have employed here the advantages of high throughput time and increased sensitivity of ultra high pressure liquid chromatography (UPLC) to develop a fully validated, fast, highly sensitive and reproducible UPLC-MS/MS method suitable for the measurement of AEA in human plasma. AEA concentrations were measured in plasma obtained from women at all stages of reproductive life and compared to data previously reported [1].

Formatted: Right: $0.63 \mathrm{~cm}$ 


\section{Materials and methods}

\section{Chemicals}

Anandamide (AEA) and octa deuterated anandamide (AEA-d8) were obtained from Cayman Chemicals (Ann Arbor, MI). Virodhamine was purchased from (Tocris Bioscience, Bristol, UK). Acetonitrile, chloroform, formic acid, ammonium acetate and methanol each of HPLC grade were purchased from Fisher Scientific (Loughborough, UK) and HPLC grade water was obtained using a water purification system (Maxima ELGA, ELGA, High Wycombe, UK). All mobile phases were filtered through $0.2 \mu \mathrm{m}, 47 \mathrm{~mm}$ diameter PTFE filters (Waters Ltd, Elstree, UK) prior to use. Saline was obtained from Fannin UK Ltd (Reading, UK).

\section{Preparation of standards}

$A E A$, virodhamine and $A E A-d 8$ stock solutions in acetonitrile at $5 \mathrm{mg} / \mathrm{mL}, 5$ $\mathrm{mg} / \mathrm{mL}$ and $100 \mu \mathrm{g} / \mathrm{mL}$, respectively were aliquoted for single use and stored at $-20^{\circ} \mathrm{C}$. Further dilutions were made in acetonitrile on ice on the day of analysis.

For calculation of the limits of detection and quantification, to overcome the presence of variable AEA concentrations in plasma, both AEA and AEA-d8 were extracted from isotonic saline. To observe the effect of the plasma matrix, the limits of detection and quantification were also determined for AEA-d8-spiked plasma.

Formatted: Right: $0.63 \mathrm{~cm}$ 


\section{UPLC/MS/MS}

The UPLC-MS/MS system comprised of an Acquity UPLC system connected inline with a Quattro Premier tandem mass spectrometer (Waters Ltd., Elstree, UK). The column utilised was an Acquity UPLC BEH $\mathrm{C}_{18}(2.1 \times 50$ $\mathrm{mm}, 1.7 \mu \mathrm{m})$ maintained at $40^{\circ} \mathrm{C}$. Mobile phases were A $(2 \mathrm{mM}$ ammonium acetate containing $0.1 \%$ formic acid) and $\mathrm{B}$ (acetonitrile containing $0.1 \%$ formic acid). LC gradient conditions were as follows: 0-0.5 min, $80 \% \mathrm{~A} ; 1.5$ min, $0 \% \mathrm{~A} ; 2.5 \mathrm{~min}, 80 \% \mathrm{~A}$ then re-equilibrated at $80 \% \mathrm{~A}$ until $3.5 \mathrm{~min}$. Samples were maintained at $4^{\circ} \mathrm{C}$ throughout.

Analytes were quantified using tandem electrospray mass spectrometry in positive ion mode $\left(\mathrm{ES}^{+}\right)$. Source parameters included capillary voltage of 0.6 $\mathrm{kV}$, cone voltage of $18 \mathrm{~V}$, source temperature of $120^{\circ} \mathrm{C}$, desolvation temperature of $440^{\circ} \mathrm{C}$, cone gas flow of $49 \mathrm{~L} / \mathrm{h}$, desolvation gas flow of 800L/h. Subsequently, MS/MS conditions for monitoring each precursor $[\mathrm{M}+\mathrm{H}]^{+}$ion comprised entry, collision and exit energies of $-2,17$ and $0 \mathrm{eV}$, respectively. Product ions were monitored in single reaction monitoring (SRM) mode. Injection volumes for samples and standards were $7 \mu$ with needle overfill. Eight-point calibration curves were performed in triplicate and AEA peaks were integrated using Masslynx software version 4.1 (Waters Inc., Milford, MA, USA, 2005). Quanlynx software (Waters Inc. Milford, MA. USA, 2005) was used to calculate the concentration of AEA using calibration curves of concentration against relative response calculated as follows:

Formatted: Right: $0.63 \mathrm{~cm}$ 


$$
\text { Relative response }(\mathrm{y})=\frac{\text { Peak area }}{(\text { IS area } /[A E A-d 8])}
$$

Where IS=the peak area of the AEA-d8 internal standard and $[A E A-d 8]=$ the concentration of the internal standard. Peak area=the peak area of AEA.

\section{Extraction of AEA from human plasma and isotonic saline}

Extractions were performed as described by Habayeb et al., (2004) with minor changes [1]. Whole blood (4 mL) was collected in EDTA tubes (Sarstedt Ltd, Leicester, UK) then immediately transported on ice to the analytical laboratory to be centrifuged at $1200 \times \mathrm{g}$ for $30 \mathrm{~min}$ at $4^{\circ} \mathrm{C}$ to separate plasma from cells. Plasma (2 mL) was transferred to a $7 \mathrm{~mL}$ Kimble scintillation vial (Kinesis, $\mathrm{St}$ Neots, Cambridge, UK). For the purpose of determining extraction efficiency, $2.5 \mathrm{pmol}$ AEA-d8 internal standards were added to $2 \mathrm{~mL}$ of plasma or saline prior to thorough mixing with a desktop vortexer. Protein was precipitated by the addition of $2 \mathrm{~mL}$ ice-cold acetone followed by centrifugation at $1200 \times \mathrm{g}$ for 10 min at $4^{\circ} \mathrm{C}$. The supernatant was transferred to a fresh Kimble scintillation vial and the acetone evaporated under a gentle stream of nitrogen gas. Lipid extraction was then performed on the remaining mixture by the addition of 2 $\mathrm{mL}$ methanol: chloroform $(1: 2 \mathrm{v} / \mathrm{v})$ followed by gentle mixing by repeated inversion. The sample was centrifuged at $1200 \mathrm{xg}$ for $10 \mathrm{~min}$ at $4^{\circ} \mathrm{C}$ and the lower chloroform layer was recovered into a fresh Kimble vial and then dried under a gentle stream of nitrogen before reconstitution in acetonitrile $(80 \mu \mathrm{l})$. To estimate the efficiency of the lipid extraction procedure, peak areas 
obtained for 2.5 pmol AEA-d8 extracted from plasma were compared with 2.5 pmol AEA-d8 standard in $80 \mu$ l acetonitrile.

\section{Validation of UPLC-MS/MS analysis of AEA}

The UPLC-MS/MS method was validated according to FDA guidelines (www.fda.gov). Linearity for the assay was determined using 15 eight-point standard curves (1.66 to $133 \mathrm{fmol}$ on column) and linear regression analysis. Consistency of the retention time was investigated after 20 injections of 133 fmol of AEA. Accuracy, defined as the deviation of observed concentration from expected, was calculated for solvent containing three concentrations of AEA; $3.33,6.65$ and $133 \mathrm{fmol}$ on the column (20 samples). Precision was calculated after 20 repeat injections of $19 \mathrm{nM}, 0.95 \mathrm{nM}$ and $0.237 \mathrm{nM}$ AEA standards in acetonitrile ( $133 \mathrm{fmol}, 6.65 \mathrm{fmol}$ and $1.66 \mathrm{fmol}$ AEA on column). Limits of quantification and detection were defined as AEA responses which yielded a signal to noise ratio, without smoothing, of greater than 10 and greater than 3, respectively and were calculated for extraction of AEA-d8 from plasma and from saline. The limits of quantification for AEA were determined only from saline because of the presence of endogenous AEA present in all plasma samples. Finally, although tandem mass spectrometry by the nature of the technique has extremely good selectivity, the detection of AEA can be complicated by the presence of virodhamine [19], another endocannabinoid, which has an identical molecular weight and which fragments to a daughter ion of comparable $\mathrm{m} / \mathrm{z}$ to AEA daughter ion (Figure 1). Consequently, it was necessary to demonstrate that virodhamine did not contribute to the AEA 
signal. Virodhamine standards were analysed to demonstrate distinct retention times for the two endocannabinoids.

\section{Comparison of Plasma AEA concentrations in women of reproductive and post-reproductive age}

For the purposes of determining changes in the plasma levels of AEA during pregnancy, we studied five groups of women in the first, second and third trimesters and women at term who were not in labour and those that were (Table 1). To minimize the potential influence of a wide gestational window on AEA levels, we restricted our sampling to $6-11$ postmenstrual weeks in the first trimester, 15-27 postmenstrual weeks in the second trimester, and 31-35 postmenstrual weeks in the third trimester. Term was defined as 39-41 completed postmenstrual weeks.

The inclusion criteria for the pregnant women were a body mass index (BMI) less than $27 \mathrm{~kg} / \mathrm{m}^{2}$, accurately dated pregnancies from first trimester ultrasound scans performed between 6 and 8 postmenstrual weeks, uncomplicated singleton pregnancies, and no co-existing medical conditions. No volunteers were taking medication or known to have taken recreational drugs. Only women in established labour (defined as cervical dilatation of at least $4 \mathrm{~cm}$ and three to four regular uterine contractions every $10 \mathrm{~min}$ ) were included in the term labouring group. The non-pregnant women were divided into two groups: pre- and post-menopausal. The inclusion criteria for the premenopausal women were regular menstrual cycles for the last 6 months, BMI less than $27 \mathrm{~kg} / \mathrm{m}^{2}$, not on any hormonal contraception or therapy for at least 
3 months, and not on any drugs or suffering from any medical disorders. The samples were collected in two subgroups based on the menstrual cycle (follicular days 2-14 and luteal days 20-30) assessed from patient-reported last menstrual period date. All these women had regular 28-30 day cycles. The inclusion criteria for the post-menopausal women were a minimum of 2 year post-menopause, BMI of less than $27 \mathrm{~kg} / \mathrm{m}^{2}$, not receiving hormone replacement therapy for the preceding 3 months, and not on any drugs such as glucocorticoids, anti-hypertensives, analgesics, recreational drugs or suffering from any medical disorders. We studied only non-obese women, defined by a BMI less than $27 \mathrm{~kg} / \mathrm{m}^{2}$, as we were uncertain about the effect of adiposity on the homeostasis of AEA. All subjects gave signed informed consent to take part in the study, which was approved and conducted according to the guidelines of the Leicestershire and Rutland Local Research Ethics Committee.

\section{Statistical Analysis}

Data are presented as the mean \pm SD throughout. Pair-wise comparison between volunteer groups was performed using two-tailed Student's t-test using Welch's correction for unequal variances within GraphPad Instat version 3, GraphPad Software, San Diego, CA, USA, www.graphpad.com. 


\section{Results and Discussion}

The combination of UPLC technology, with small pore sized stationary phase running at higher pressures, and Quattro premier mass spectrometer were employed here to develop a highly sensitive method for the analysis of AEA in plasma. A number of different mobile phases including methanol, acetonitrile and ethanol were utilised in method development. Acetonitrile was found to be the most sensitive for the measurement of AEA and AEA-d8.

Similarly, several isocratic systems were also investigated, but none could reproduce the sensitivity (response) and peak symmetry obtained with the method described here. Mobile phases were acidified to reduce formation of sodium adducts and consequently the strongest MRM transitions found for AEA and AEA-d8 were $\mathrm{m} / \mathrm{z} 348.3>62.3$ and $\mathrm{m} / \mathrm{z} 356.3>63.3$, respectively which is proposed to represent the cleavage releasing ethanolamide (Figure 1). This observation is consistent with the observations of Richardson et al., (2007) [19] who found $m / z 356.33>63.1$ to be the optimal transition for AEAd8. Spectra of the parent ion and daughter ion scans for AEA, AEA-d8 and virodhamine are presented in Figure 2. As can be seen, the daughter ions employed in the transitions for this method are the predominant fragments observed for each compound. The 356.33>63.2 transition implies that in AEAd8 there is intra-molecular transfer of a deuterium ion to the ethanolamide side chain from the arachidonyl component of AEA-d8. Furthermore, the masses for virodhamine are identical to those of $A E A$ and the method described here consequently detects both endocannabinoids (Figure 3C). 
Multiple injections of AEA standards demonstrated that of a range of capillary voltages, from $0.6 \mathrm{kV}$ to $3.0 \mathrm{kV}, 0.6 \mathrm{kV}$ was found to provide the optimal signal for the anandamide transitions (data not shown). Similarly, flow rates of 0.5$1.0 \mathrm{~mL} / \mathrm{min}$ were investigated but $0.7 \mathrm{~mL} / \mathrm{min}$ yielded results with the greatest peak height and signal-to-noise ratio (data not shown).

AEA and AEA-d8 are supplied as standard solutions in ethanol and in methyl acetate, respectively. The integrity of these standards was compromised by evaporation once the sample had been opened (data not shown). We observed continued stability and improved reproducibility of signal response, if the authentic material and internal standards were dried under a gentle stream of nitrogen and then re-dissolved in acetonitrile. Aliquots suitable for daily use were created and stored at $-20^{\circ} \mathrm{C}$, under nitrogen. All further sample handling was conducted on ice.

\section{Validation of UPLC/MS/MS analysis of AEA}

AEA and AEA-d8 were both eluted from the UPLC and detected by MS/MS at $1.67 \pm 0.0009 \mathrm{~min}$ after injection (Figure 3 ) and had an observed relative standard deviation (RSD) of $0.05 \%$ for the retention time after 20 injections. Retention time was consistent over the lifetime of the column which represented in excess of 9000 injections. A very minor peak, eluting prior to AEA (1.65 min) was routinely observed in samples extracted from plasma (Figure 3D). The identity of this peak was thought to be the related endocannabinoid virodhamine (Figure 1) which has an identical molecular weight to $\mathrm{AEA}$ and fragments to the same daughter ion (Figure 3C) [19]. 
However, using authentic virodhamine standards we demonstrate that virodhamine did not contribute to the 1.65 min peak in our analyses. Coinjection of virodhamine with AEA demonstrated two clearly separated peaks with virodhamine eluting $1.52 \mathrm{~min}$ after injection (Figure 3C). Consequently, the identity of the peak at $1.65 \mathrm{~min}$ is unknown.

Linearity as derived from calibration curves $(n=15)$ was described by the equation Response $(y)=(2.48 \pm 0.14)[A E A] n M+(0.004 \pm 0.04)$ with mean $r^{2}$ value of 0.999 . The response was linear over the non-extracted concentration range of 1.66 to $133 \mathrm{fmol}$ on column (equivalent to $0.23-19 \mathrm{nM}$ ). Precision for the $133 \mathrm{fmol}$ injection of AEA (19 $\mathrm{nM}$ ) on column (20 injections) was calculated to have a mean of $19 \mathrm{nM} \pm 0.70$ with a relative standard deviation (RSD) of $3.7 \%$ which is the best precision described for the measurement of AEA. Similarly, precision for 20 injections of $0.24 \mathrm{nM}(1.66 \mathrm{fmol})$ and $0.95 \mathrm{nM}$ (6.65 fmol) which resemble the lower AEA concentrations observed in plasma yielded mean values of $0.238 \pm 0.009 \mathrm{nM}$ and $0.945 \pm 0.046 \mathrm{nM}$, with RSD of 3.9 and $4.8 \%$, respectively.

For non-extracted AEA and AEA-d8, limits of quantification (LOQ) were 0.22 fmol on column (a signal to noise ratio > 10) and the limits of detection (LOD) were $0.055 \mathrm{fmol}$ on column (signal to noise ratio $=3$ ). These represent improvements of an order of magnitude over the previous best LOD (Table 2) [19]. On column, the accuracy for $3.33 \mathrm{fmol}$ of AEA was $97.5 \pm 9.5 \%, 98.5 \pm$ $6.1 \%$ for $6.65 \mathrm{fmol}$ and was $104.5 \pm 3.2 \%$ for $133 \mathrm{fmol}$. In Figures $4 \mathrm{~A}$ and $4 \mathrm{~B}$ spectra demonstrating the LOD and LOQ for the extraction of AEA-d8 from 2 
$\mathrm{mL}$ of plasma are shown to be $18.75 \mathrm{fmol} / \mathrm{mL}$ (a signal to noise ratio $>3$ ) and $25 \mathrm{fmol} / \mathrm{mL}$ (a signal to noise ratio > 10), respectively. Likewise, AEA and AEA-d8 extracted from saline yielded LOD and LOQ values of $0.78 \mathrm{fmol} / \mathrm{mL}$ (signal to noise ratio $>3$ ) and $6.25 \mathrm{fmol} / \mathrm{mL}$ (signal to noise ratio $>10$ ), respectively. This sensitivity is a marked improvement on previous published methods (Table 2) and implies that smaller plasma samples could be used in analysis or that this method could be employed to analyse biomatrices with significantly lower AEA concentrations.

The significantly less sensitive limits of detection and quantification for AEAd8 measurement following extraction from plasma compared with extraction from saline demands further investigation. LOD and LOQ for plasma samples are conservative here because it was decided to employ a relatively large resuspension volume $(80 \mu \mathrm{L})$ and three injections of each sample $(7 \mu \mathrm{L})$ with needle overfill, to maintain a high degree of accuracy and reproducibility. Consequently, if desired, the lower limits of detection and quantification for plasma AEA-d8 and AEA could be improved by re-suspending the extracted samples in a smaller final volume of acetonitrile.

The method described here represents the shortest analysis time for any method published to date for the analysis of AEA in a biological matrix. When compared with the next fastest method, the run time employed here represents an improvement of over $4 \mathrm{~min} / \mathrm{per}$ injection previously for measurement of AEA [18]. Furthermore, this method represents a marked 
improvement in LOQ, LOD, precision and accuracy when compared with previously validated methods (Table 2 ).

\section{Comparison of Plasma AEA concentrations in women of reproductive and post-reproductive age with a previous HPLC-MS method}

To show the immediate applicability of this method AEA was measured in 88 normal, healthy, female volunteers with plasma concentrations ranging from 0.45 to $3.98 \mathrm{nM}$ AEA. No virodhamine was detected in any samples.

The data indicate that the levels of plasma AEA in women of reproductive and post-reproductive age were similar to those previously obtained using a standard HPLC-MS method (Figure 5) [1]. There was a significant $(P=0.0078)$ reduction in plasma AEA levels during the menstrual cycle from follicular phase $(1.45 \pm 0.81 \mathrm{nM})$ to luteal phase $(0.77 \pm 0.30 \mathrm{nM})$, in agreement with previously published data [1]. Low AEA concentrations are reported to be essential for successful implantation and pregnancy progression [22-24] and these data demonstrate that in the luteal phase of the menstrual cycle plasma AEA levels are established at concentrations favouring successful pregnancy. Levels of AEA in plasma obtained from post-menopausal women (0.96 \pm $0.19 \mathrm{nM}$ ) closely resembled concentrations during the luteal phase in premenopausal women and were likewise significantly lower $(P=0.0389)$ than follicular phase AEA concentrations. These low concentrations of AEA in post-menopausal women imply a role for reproductive hormones in the regulation of plasma AEA concentrations and taken together with the higher levels observed in follicular phase suggests roles for estradiol in increasing

Formatted: Right: $0.63 \mathrm{~cm}$ 
plasma AEA levels and for progesterone in decreasing these levels. Indeed, estradiol has been shown to mediate the release of AEA from endothelial cells into the circulation and progesterone has been shown to decrease plasma AEA thereby providing substantial supportive evidence for this notion [25].

AEA concentrations in the first $(0.91 \pm 0.28 \mathrm{nM})$ and second $(0.91 \pm 0.30 \mathrm{nM})$ trimesters did not differ significantly from levels observed in the luteal phase of he menstrual cycle (Figure 5). This observation is expected as previous studies indicate that low AEA levels are required for IVF pregnancies to progress beyond the first trimester [22] and high levels of AEA are associated with miscarriages [23]. The plasma levels in women within the second and third trimester of pregnancy were previously shown claimed by our group to be significantly lower than those in women within the first trimester [1] however; this was not shown by this method. The improved sensitivity of the UPLC-MS/MS method described herein may in some ways explain the discrepancy between the present and previous data as the LOQ for the LC/MS method employed in the previous publication was close to the observed plasma concentrations $[1,15]$, whereas the LOQ for this method $(25$ $\mathrm{pM}$ ) is more than an order of magnitude below the lowest plasma measurement of $0.45 \mathrm{nM}$ in the volunteers. The increased sensitivity allows for better precision in the measurement of plasma levels.

A significant alteration in the levels of plasma AEA was also observed in women in active labour. The mean value of $2.30 \mathrm{nM}$ was $\sim 1.7$-fold higher than that found in women at term but not in labour (Figure 5). These data are in

Formatted: Right: $0.63 \mathrm{~cm}$ 
general agreement with the previously published AEA levels in these groups of women [1].

The role of AEA at the time of labour is currently unknown, but it may be acting as a reservoir for arachidonic acid, a precursor of prostaglandins, an increase in which is observed in the uterus during labour [26].

\section{Conclusions}

In conclusion, the combination of UPLC with MS/MS has yielded a method for the analysis of AEA at concentrations found in plasma with a sensitivity, reproducibility and precision that are improvements on previous methods and which make this method suitable for analysis of clinical samples. The improved sensitivity suggests that this method could be used for the analysis of $A E A$ in reduced sample volumes or in biomatrices with lower levels of AEA. The faster analysis time for this method represents a saving both financially (solvents, labour time) and in time, allowing the analysis of larger sample numbers. The changes in plasma AEA concentration observed in the initiation and maintenance of pregnancy and during labour in a new cohort of women are further supportive evidence of our previous contention that endocannabinoids may be key regulators of these processes.

Formatted: Right: $0.63 \mathrm{~cm}$ 


\section{Acknowledgments}

This work was funded in part by generous grants from Perkin-Elmer and the

British United Provident Association (BUPA) Foundation. We are grateful to the technical staff at Waters Ltd (Manchester, UK) for their expert assistance.

Formatted: Right: $0.63 \mathrm{~cm}$ 


\section{Figure Legends}

Figure 1 Structures of AEA and virodhamine showing the proposed site of fragmentation during UPLC/MS/MS and sites of deuteration in AEA-d8.

Figure 2: Parent and daughter ion mass spectra for AEA, AEA-d8 and virodhamine.

Figure 3: (A) UPLC-MS/MS spectrograms of an AEA standard in acetonitrile ( $m / z$ 348.3>62.3); (B) an AEAd8 standard in acetonitrile ( $\mathrm{m} / \mathrm{z} 356.3>63.3)$; (C) AEA standard $(19 n M)$ spiked with $9 \mathrm{nM}$ virodhamine in acetonitrile $(\mathrm{m} / \mathrm{z}$ 348.3>62.3; (D) AEA extracted from $2 \mathrm{~mL}$ human plasma ( $\mathrm{m} / \mathrm{z} 348.3>62.3$ ); and (E) AEA-d8 internal standard extracted from $2 \mathrm{~mL}$ human plasma $(\mathrm{m} / \mathrm{z}$ 356.3>63.3). * indicates unknown peak present in human plasma.

Figure 4: Detection by UPLC-MS/MS of low levels of AEA and AEA-d8 extracted from plasma and saline. Spectrograms are representative of five injections of: (A) AEA-d8 extracted from plasma at the limit of detection (LOD) $(18.75 \mathrm{fmol} / \mathrm{mL})$; (B) AEA-d8 extracted from plasma at the limit of quantification (LOQ) (25fmol/mL); (C) AEA-d8 extracted from saline at the limit of detection $(0.78 \mathrm{fmol} / \mathrm{mL})$; (D) AEA extracted from saline at the limit of detection $(0.78 \mathrm{fmol} / \mathrm{mL})$; (E) AEA-d8 extracted from saline at the limit of quantification $(6.25 \mathrm{fmol} / \mathrm{mL})$; and $(\mathbf{F})$ AEA extracted from saline at the limit of quantification $(6.25 \mathrm{fmol} / \mathrm{mL})$. 
Figure 5: Comparison of the plasma AEA concentrations in adult women at different stages of the menstrual cycle and pregnancy. The volunteer demographics and numbers are described in Table 1. Data are presented as the mean \pm SD. Pair-wise comparison was performed using two-tailed paired Students' t-test with Welch's correction for uneven variances $\left({ }^{*} P=0.0389\right.$ and ${ }^{* *} P=0.0078$ compared to follicular phase levels; $\uparrow P=0.0147$ compared to term non-labouring levels.)

Formatted: Right: $0.63 \mathrm{~cm}$ 
Table 1. Distribution, age, and gestational age of the study groups

\begin{tabular}{lcc}
\hline Study group & $\mathrm{n}$ & $\begin{array}{c}\text { Gestational age } \\
\text { [weeks] }\end{array}$ \\
\hline First trimester & 7 & $7.8(6-11)$ \\
Second trimester & 14 & $20.7(15-27)$ \\
Third trimester & 8 & $33(31-35)$ \\
Term (not labouring) & 8 & $40(39-41)$ \\
Term (labouring) & 8 & $40(39-41)$ \\
Menstrual cycle & 15 & n.a. \\
(follicular) & 15 & n.a. \\
Menstrual cycle & & n.a. \\
(luteal) & 13 & Postmenopausal \\
Data are presented as means with (ranges); n.a.=not applicable;
\end{tabular}

Formatted: Right: $0.63 \mathrm{~cm}$ 
Table 2. Comparison of the UPLC-MS/MS AEA measurement method with data obtained in two recently described LC-MS/MS methods

\begin{tabular}{|c|c|c|c|}
\hline & $\begin{array}{l}\text { Richardson et al } \\
2007 \dagger\end{array}$ & $\begin{array}{l}\text { Vogeser et al } \\
2006\end{array}$ & UPLC-MS/MS \\
\hline Range & $\begin{array}{l}25 \mathrm{fmol}^{\#-250} \\
\mathrm{pmol}^{\#}\end{array}$ & $\begin{array}{l}0.069-4.32 \\
\text { pmol }^{\#}\end{array}$ & $1.66-133 \mathrm{fmol}^{\#}$ \\
\hline Linearity & $R^{2}=0.992$ & nd & $\begin{array}{l}Y=2.48 \pm 0.14 x+ \\
(0.004 \pm 0.04) \\
R^{2}=0.999\end{array}$ \\
\hline $\begin{array}{l}\text { Precision } \\
\text { (RSD) }\end{array}$ & $\begin{array}{l}13.6 \% \\
(20 \mathrm{pmol} / \mathrm{g})\end{array}$ & $\begin{array}{l}6.8 \% \\
\left(180 \mathrm{fmol}^{\#}\right) \\
5.3 \% \\
\left(1097 \mathrm{fmol}^{\#}\right)\end{array}$ & $\begin{array}{l}3.9 \%\left(1.66 \mathrm{fmol}^{\#}\right) \\
4.8 \%\left(6.65 \mathrm{fmol}{ }^{\prime}\right) \\
3.7 \%(133 \mathrm{fmol})\end{array}$ \\
\hline $\begin{array}{l}\text { LOQ } \\
\text { LOD } \\
\text { Accuracy }\end{array}$ & $\begin{array}{l}10 \mathrm{pmol} / \mathrm{g}^{*} \\
25 \mathrm{fmol} \mathrm{I}^{\#} \\
65-155 \%\end{array}$ & $\begin{array}{l}\text { nd } \\
43 \mathrm{fmol}^{\#} \\
\text { nd }\end{array}$ & $\begin{array}{l}25.0 \mathrm{fmol} / \mathrm{mL} \text { plasma } \\
18.75 \mathrm{fmol} / \mathrm{mL} \text { plasma } \\
97.5 \pm 9.5 \%\left(3.33 \mathrm{fmol}^{\#}\right) \\
98.5 \pm 6.1 \%\left(6.65 \mathrm{fmol}^{\#}\right) \\
104.5 \pm 3.2 \%(133 \\
\left.\mathrm{fmol}^{\#}\right)\end{array}$ \\
\hline $\begin{array}{l}\text { Runtime } \\
\text { (min) }\end{array}$ & 15 & 7 & 4 \\
\hline
\end{tabular}

† Represents data for extractions from brain tissues. n.d.=not determined.

* rat brain tissue. " Represents values as mass of AEA on column. 


\section{References}

[1] O.M.H. Habayeb, A.H. Taylor, M.D. Evans, M.S. Cooke, D.J. Taylor, S.C.

Bell, J.C. Konje, Plasma levels of the endocannabinoid anandamide in women-A potential role in pregnancy maintenance and labor? J. Clin. Endocrinol. Metab.89 (2004) 5482-5487.

[2] W.A. Devane, L. Hanus, A. Breuer, R.G. Pertwee, L.A. Stevenson, G. Griffin, D. Gibson, A. Mandelbaum, A. Etinger, R. Mechoulam, Isolation and structure of a brain constituent that binds to the cannabinoid receptor. Science 258 (1992) 1946-1949.

[3] V. Di Marzo, "Endocannabinoids" and other fatty acid derivatives with cannabimimetic properties: biochemistry and possible physiopathological relevance. Biochim. Biophys. Acta 1392 (1998) 153-175.

[4] L. Hanus, A. Saleh, E. Fride, A. Breuer, Z. Vogel, D.E. Shalev, I. Kustanovich, R. Mechoulam, 2-Arachidonyl glyceryl ether, an endogenous agonist at the cannabinoid receptor. Proc. Natl. Acad. Sci. USA 98 (2001) 3662-3665.

[5] T. Bisogno, D. Melck, M. Yu. Bobrov, N. M. Gretskaya, V. V. Bezuglov, L. De Petrocellis, V. Di Marzo, $\mathrm{N}$-acyl-dopamines: novel synthetic $\mathrm{CB}_{1}$ cannabinoid-receptor ligands and inhibitors of anandamide inactivation with cannabimimetic activity in vitro and in vivo, Biochem. J. 351 (2000) 817-824. 
[6] D. Piomelli, The molecular logic of endocannabinoid signalling, Nat. Rev. Neurosci. 4 (2003) 873-884.

[7] M. Beltramo, N. Stella, A. Calignano, S.Y. Lin, A. Makriyannis, D. Piomelli, Functional role of high-affinity anandamide transport, as revealed by selective inhibition, Science 277 (1997) 1094-1097.

[8] P.M. Zygmunt, J. Petersson, D.A. Andersson, H-H.Chuang, M. Sørgård, V. Di Marzo, D. Julius, E.D. Högestätt, Vanilloid receptors on sensory nerves mediate the vasodilator action of anandamide, Nature 400 (1999) 452-457.

[9] P. Pacher, S. Bátkai, G. Kunos, The endocannabinoid system as an emerging target of pharmacotherapy, Pharmacol. Rev. 58 (2006) 389-462

[10] B. Zuckerman, D.A. Frank, R. Hingson, H. Amaro, S.M. Levenson, H. Kayne, S. Parker, R. Vinci, K. Aboagye, L.E. Fried, H. Cabral, R. Timperi, H. Bauchner, Effects of maternal marijuana and cocaine use on fetal growth, $\mathrm{N}$. Engl. J. Med. 320 (1989) 762-768.

[11] D.A. Frank, H. Bauchner, S. Parker, A.M. Huber, K. Kyei-Aboagye, H. Cabral, B. Zuckerman, Neonatal body proportionality and body composition after in utero exposure to cocaine and marijuana, J Pediatr 117 (1990) 622626. 
[12] E.F. McCance-Katz, The consequences of maternal substance abuse for the child exposed in utero, Psychosomatics 32 (1991) 268-274.

[13] M. Maccarrone, T. Bisogno, H. Valensise, N. Lazzarin, F. Fezza, C. Manna, V. Di Marzo, A. Finazzi-Agro, Low fatty acid amide hydrolase and high anandamide levels are associated with failure to achieve an ongoing pregnancy after IVF and embryo transfer, Mol. Hum. Reprod. 8 (2002) 188195.

[14] H. Wang, S.K. Dey, M. Maccarrone, Jekyll and Hyde: two faces of cannabinoid signalling in female fertility, Endocrine Reviews 27 (2006) 427448.

[15] A. Giuffrida, F. Rodriguez de Fonseca, D. Piomelli, Quantification of bioactive acylethanolamides in rat plasma by electrospray mass spectrometry, Anal. Biochem. 280 (2000) 87-93.

[16] A. Schmidt, K. Brune, B. Hinz, Determination of the endocannabinoid anandamide in human plasma by high-performance liquid chromatography, Biomedical Chromatography 20 (2006) 336-342.

[17] H. Schuel, L.J. Burkman, J. Lippes, K. Crickard, E. Porester, D. Piomelli, A. Giuffrida, N-Acylethanolamines in human reproductive fluids, Chemistry and Physics of Lipids 121 (2002) 211-227.

Formatted: Right: $0.63 \mathrm{~cm}$ 
[18] C.M. Fernandez-Rodriguez, J. Romero, T.J. Petros, H. Bradshaw, J.M. Gasalla, M.L. Gutierrez et al., Circulating endogenous cannabinoid anandamide and portal, systemic and renal hemodynamics in cirrhosis, Liver Int. 24 (2004) 477-483.

[19] D. Richardson, C.A. Ortori, V. Chapman, D.A. Kendall, D.A. Barrett, Quantitative profiling of endocannabinoids and related compounds in rat brain using liquid chromatography-tandem electrospray ionisation mass spectrometry, Anal. Biochem. 360 (2007) 216-226.

[20] M. Vogesser, D. Hauer, S C Azad, E. Huber, M. Storr, G. Schelling. Release of anandamide from blood cells, Clin. Chem. Lab. Med 44(4) (2006) $488-491$.

[21] N. De Marchi, L. De Petrocelis, P. Orlando, F. Daniele, F. Fezza, V. Di Marzo, Endocannabinoid signalling in the blood of patients with schizophrenia, Lipids Health Dis. 2 (2003) 5.

[22] M. Maccarrone, T. Bisogno, H. Valensise, N. Lazzarin, F. Fezza, C. Manna, V. Di Marzo, A. Finazzi-Agro, Low fatty acid amide hydrolase and high anandamide levels are associated with failure to achieve an ongoing pregnancy after IVF and embryo transfer, Mol. Hum. Reprod. 8 (2002) 188195.

Formatted: Right: $0.63 \mathrm{~cm}$ 
[23] M. Maccarrone, H. Valensise, M. Bari, N. Lazzarin, N. Romanini, A. Finazzi-Agro, Relationship between decreased anandamide hydrolase concentrations in human lymphocytes and miscarriage, Lancet 355 (2000) 1326-1329.

[24] Z.M. Yang, B.C. Paria, S.K. Dey, Activation of brain-type cannabinoid receptors interferes with preimplantation mouse embryo development, Biol. Reprod. 55 (1996) 756-761.

[25] M. Maccarrone, M. Bari, N. Battista, A. Finazzi-Agro, Estrogen stimulates arachidonoylethanolamide release from human endothelial cells and platelet activation, Blood 100 (2002) 4040-4048.

[26] J.R. Challis, D.M. Sloboda, N, Alfaidy, S.J. Lye, W. Gibb, F.A. Patel, W.L. Whittle, J.P. Newnham, Prostaglandins and mechanisms of preterm birth, Reproduction 124 (2002) 1-17.

Formatted: Right: $0.63 \mathrm{~cm}$ 
Figure 1
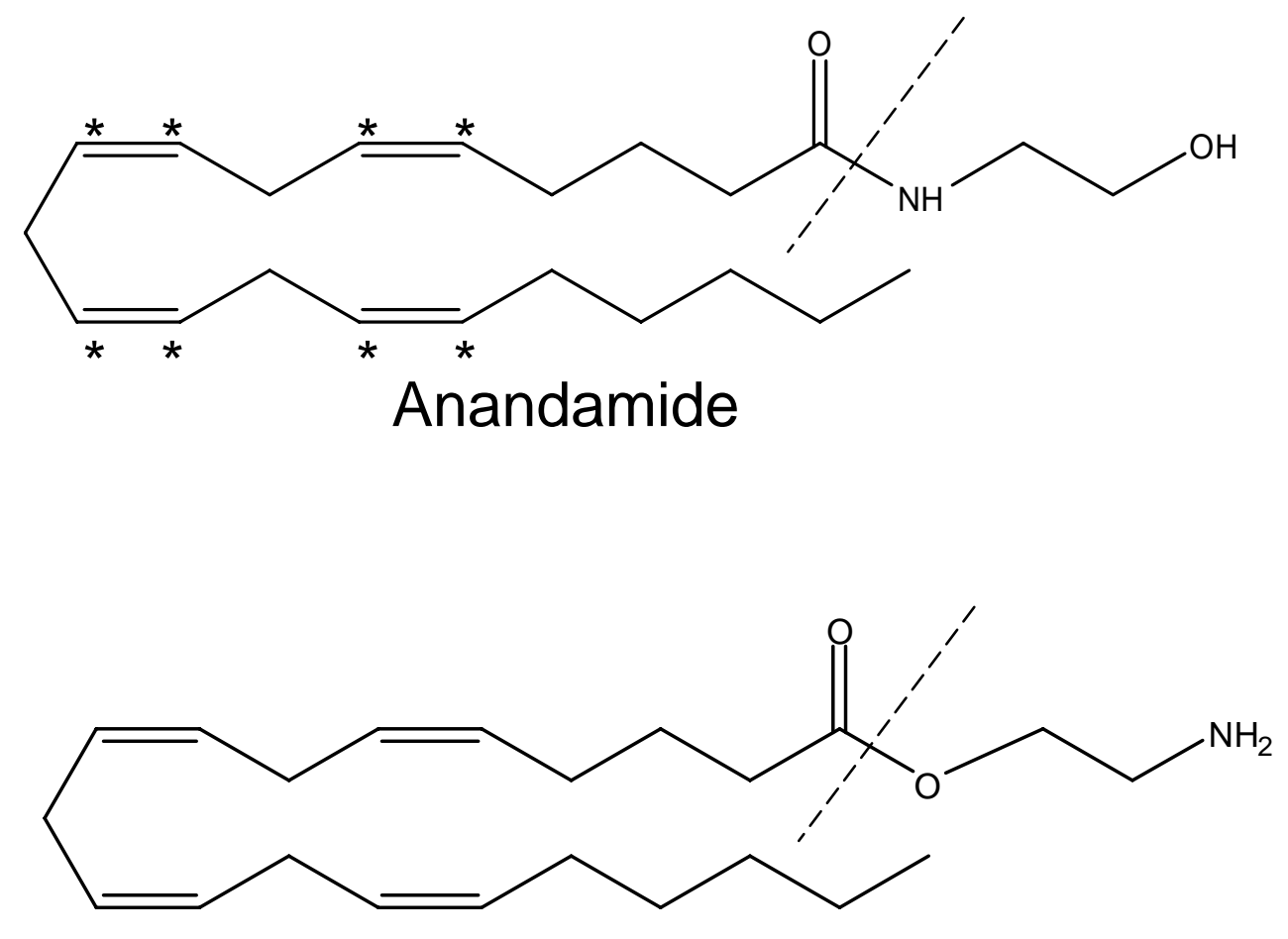

Virodhamine 


\section{Figure 2}

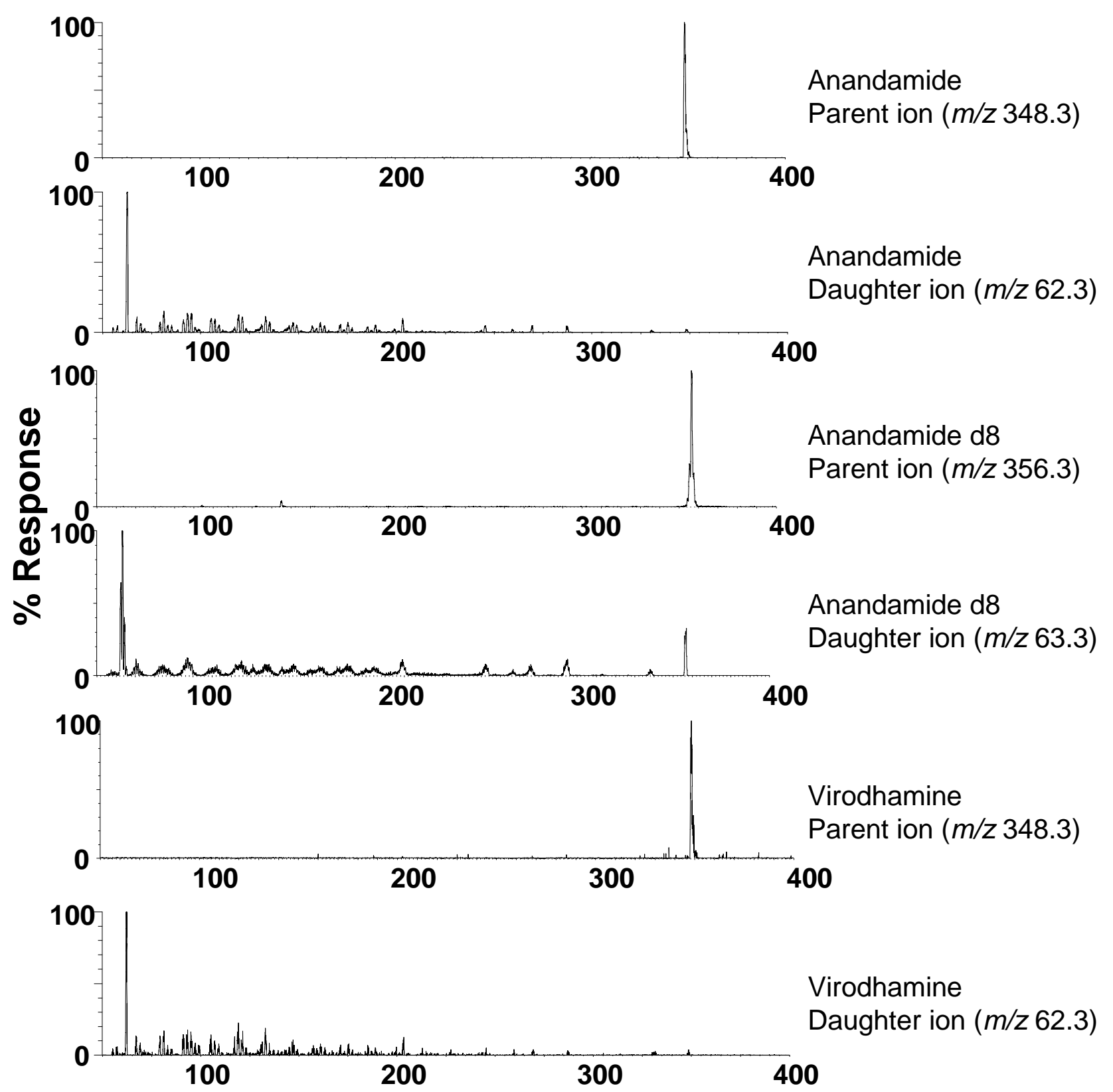




\section{Figure 3}
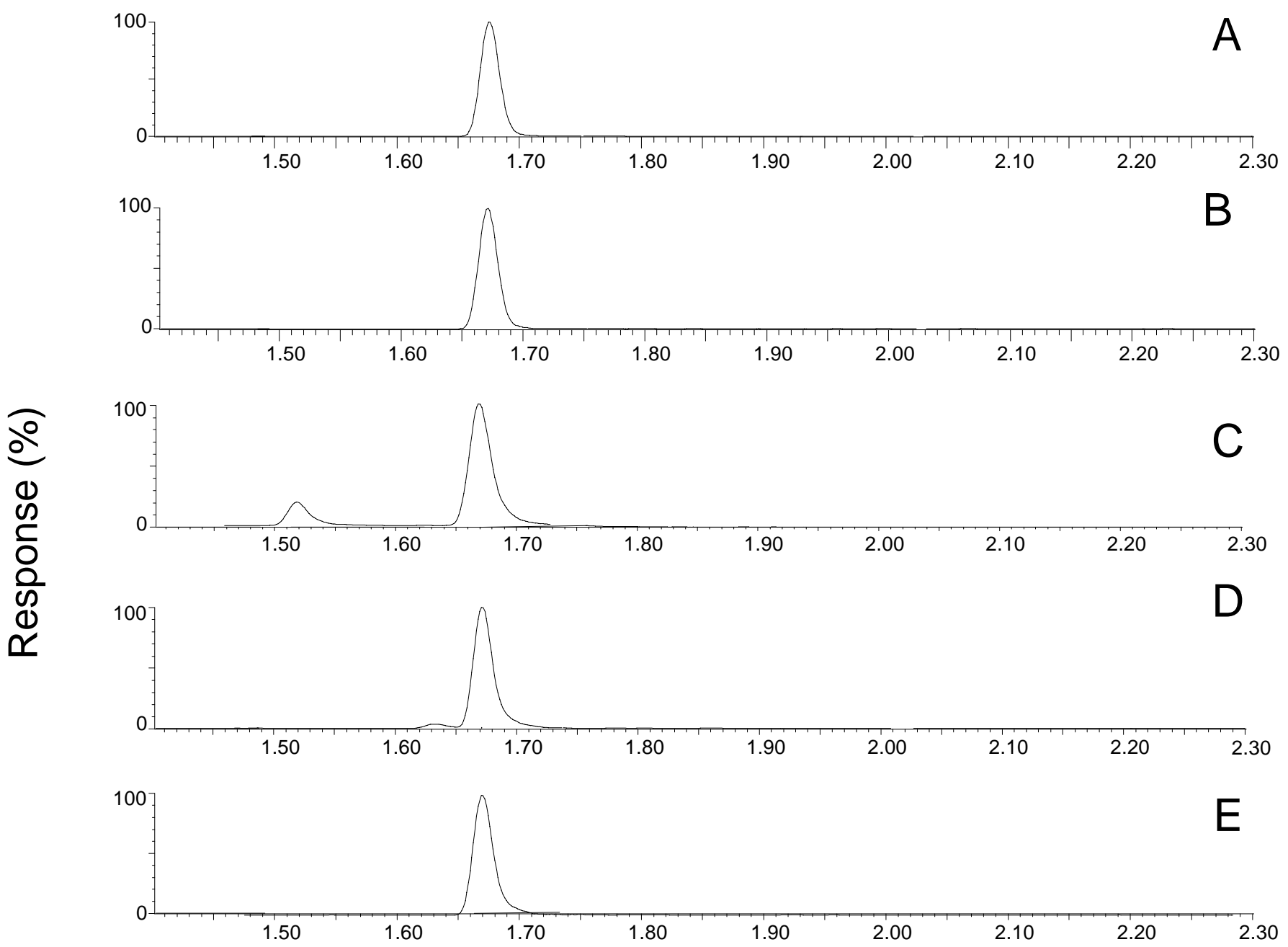

Time (min) 
Figure 4

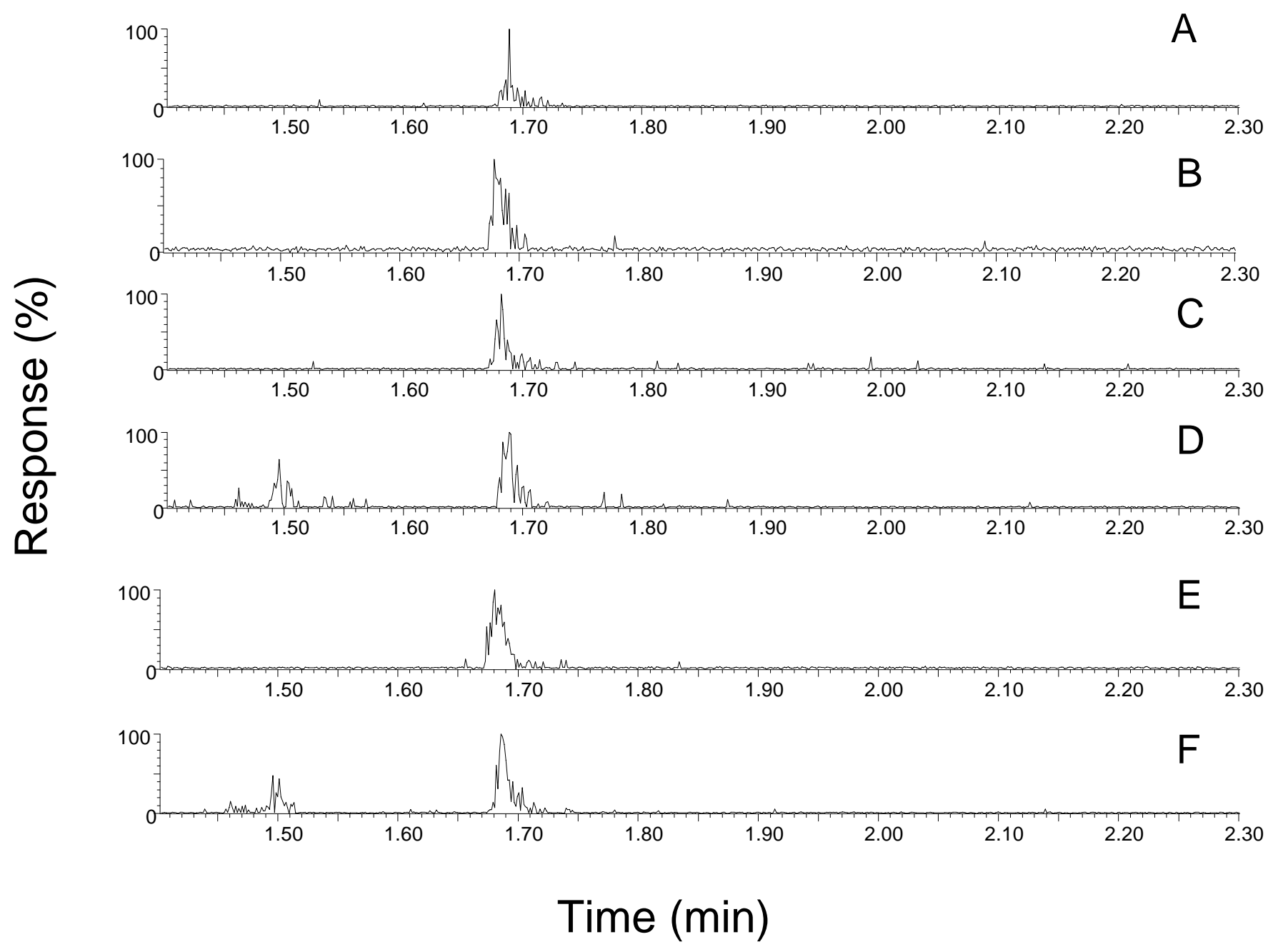


Figure 5

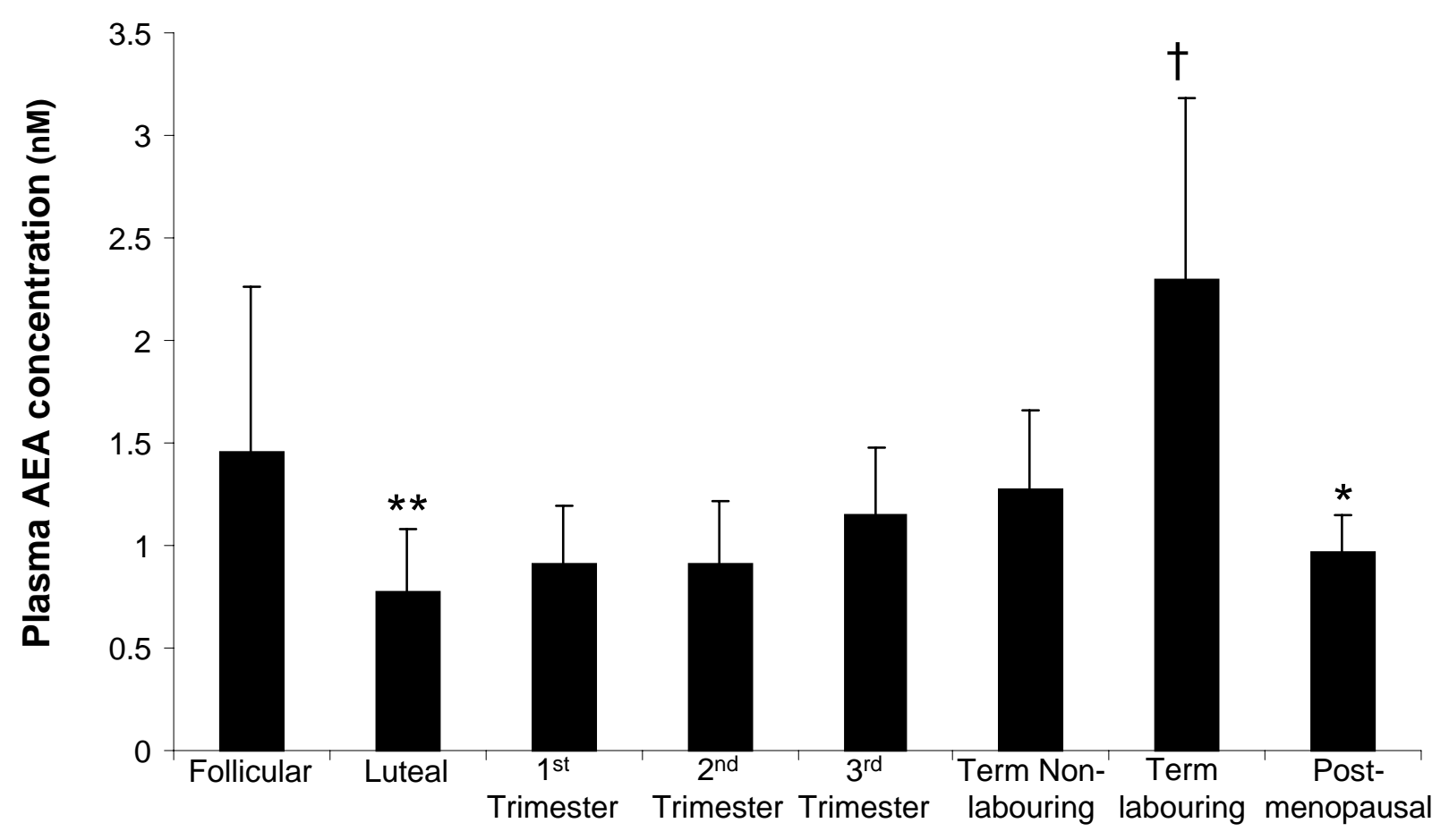

